\title{
Hepatocellular carcinoma and intrahepatic cholangiocarcinoma incidence between 2006 and 2015 in China: estimates based on data from 188 population-based cancer registries
}

\author{
Lan An ${ }^{1}$, Rongshou Zheng ${ }^{1}$, Siwei Zhang ${ }^{1}$, Ru Chen ${ }^{1}$, Shaoming Wang ${ }^{1}$, Kexin Sun ${ }^{1}$, Lingeng Lu ${ }^{2}$, \\ Xuehong Zhang ${ }^{3,4}$, Hong Zhao ${ }^{5}$, Hongmei Zeng ${ }^{1}$, Wenqiang $\mathrm{Wei}^{1}$, Jie $\mathrm{He}^{6}$
}

${ }^{1}$ National Central Cancer Registry, National Cancer Center/National Clinical Research Center for Cancer/Cancer Hospital, Chinese Academy of Medical Sciences and Peking Union Medical College, Beijing, China; ${ }^{2}$ Department of Chronic Disease Epidemiology, Yale School of Public Health, Yale Cancer Center, Yale University, New Haven, CT, USA; ${ }^{3}$ Channing Division of Network Medicine, Department of Medicine, Brigham and Women's Hospital and Harvard Medical School, Boston, MA, USA; ${ }^{4}$ Department of Nutrition, T. H. Chan School of Public Health, Harvard University, Boston, MA, USA; ${ }^{5}$ Department of Hepatobiliary Surgery, National Cancer Center/National Clinical Research Center for Cancer/ Cancer Hospital, Chinese Academy of Medical Sciences and Peking Union Medical College, Beijing, China; ${ }^{6}$ Department of Thoracic Surgery, National Cancer Registry Office, National Cancer Center/National Clinical Research Center for Cancer/Cancer Hospital, Chinese Academy of Medical Sciences and Peking Union Medical College, Beijing, China

Contributions: (I) Conception and design: H Zeng, W Wei, J He, H Zhao, L Lu, X Zhang; (II) Administrative support: R Zheng, S Zhang, H Zeng, W Wei, J He; (III) Provision of study materials or patients: R Zheng, S Zhang, R Chen, S Wang, K Sun; (IV) Collection and assembly of data: R Zheng, S Zhang, R Chen, S Wang, K Sun; (V) Data analysis and interpretation: L An, R Zheng; (VI) Manuscript writing: All authors; (VII) Final approval of manuscript: All authors.

Correspondence to: Prof. Hongmei Zeng, PhD. National Central Cancer Registry, National Cancer Center/National Clinical Research Center for Cancer/Cancer Hospital, Chinese Academy of Medical Sciences and Peking Union Medical College, 17 South Lane, Panjiayuan, Chaoyang District, Beijing 100021, China. Email: hongmeizeng@cicams.ac.cn; Prof. Wenqiang Wei, PhD. National Central Cancer Registry, National Cancer Center/ National Clinical Research Center for Cancer/Cancer Hospital, Chinese Academy of Medical Sciences and Peking Union Medical College, 17 South Lane, Panjiayuan, Chaoyang District, Beijing 100021, China. Email: weiwq@cicams.ac.cn; Prof. Jie He, MD. Department of Thoracic Surgery, National Cancer Center/National Clinical Research Center for Cancer/Cancer Hospital, Chinese Academy of Medical Sciences and Peking Union Medical College, 17 South Lane, Panjiayuan, Chaoyang District, Beijing 100021, China. Email: hejie@cicams.ac.cn.

Background: Hepatocellular carcinoma (HCC) and intrahepatic cholangiocarcinoma (ICC) are the most common subtypes of primary liver cancer, but nationwide incidence of both liver cancer subtypes have never been reported in China. We aimed to estimate the most recent incidence of HCC and ICC and temporal trends in China based on the most updated data from high qualified population-based cancer registries (covering $13.1 \%$ of the national population), in comparison to those in the United States at the same period.

Methods: We used data from 188 Chinese population-based cancer registries covering 180.6 million population of China to estimate the nationwide incidence of HCC and ICC in 2015. And 22 populationbased cancer registries' data were used to estimate the trends of HCC and ICC incidence from 2006 to 2015. Multiple imputation by chained equations method was used to impute liver cancer cases with unknown subtype $(50.8 \%)$. We used data from 18 population-based registries from the Surveillance, Epidemiology, and End Results program to analyze incidence of HCC and ICC in the United States.

Results: In China, an estimated 301,500 and 61,900 newly diagnosed HCC and ICC occurred in 2015. The overall age-standardized rates (ASRs) of HCC incidence decreased by $3.9 \%$ per year. For ICC incidence, the overall ASR was relatively stable, but increased in the population of over 65 years old. Subgroup analysis by age showed that the ASR of HCC incidence had the sharpest decline in population who were less than 14 years old and received neonatally hepatitis B virus (HBV) vaccination. In the United States, though the incidence of HCC and ICC were lower than those in China, the overall HCC and ICC incidence increased by $3.3 \%$ and $9.2 \%$ per year.

Conclusions: China still faces with a heavy burden of liver cancer incidence. Our results may further support the beneficial effect of Hepatitis B vaccination on reduction of HCC incidence. Both healthy lifestyle 
promotion and infection control are needed for future liver cancer control and prevention for China and the United States.

Keywords: Hepatocellular carcinoma (HCC); intrahepatic cholangiocarcinoma (ICC); incidence; China; trend

Submitted Feb 22, 2021. Accepted for publication Jun 03, 2021. Published online Jul 21, 2021.

doi: $10.21037 / \mathrm{hbsn}-21-75$

View this article at: https://dx.doi.org/10.21037/hbsn-21-75

\section{Introduction}

Liver cancer is the sixth most common cancer worldwide, with more than 905,000 new cases occurring annually (1). China has the world's largest liver cancer burden and more than $40 \%$ of world's new liver cancer cases occur in China (1). Although a significantly decreasing trend in liver cancer incidence was observed recently in China, high prevalence of hepatitis B virus (HBV) infection, population growth and aging still lead to a large and rising number of new cases $(2,3)$. Hepatocellular carcinoma (HCC) and intrahepatic cholangiocarcinoma (ICC) are the most common subtypes of primary liver cancer (4). Both diseases share some common risk factors including chronic infection with $\mathrm{HBV}$ and/or hepatitis C virus (HCV), cirrhosis, heavy alcohol drinking, and smoking (4-7). Additionally, the specific risk factors for ICC exist, for example, choledochal cysts, primary sclerosing cholangitis, hepatolithiasis, parasitic infections, and occupational exposure to thorotrast (4). Given that HCC and ICC are two different diseases with some specific risk factors, trends of HCC and ICC burden in one country may be different. For instance, Thailand and Italy showed rising incidence of ICC in the past decades, in contrast to a stable or declining incidence of $\operatorname{HCC}(8,9)$. Besides, it is reported that there is a significant difference in liver cancer's risk factors between eastern and western countries, which may lead to disparity in disease burden (10). China and the United States, which represent two different countries with different risk-factor distribution, may show the different trends in liver cancer incidence.

Previous study has not yet examined the trends and incidence patterns of liver cancer by histologic subtypes in China. In this study, we used the most updated data from nationwide population-based cancer registries in China, covering 180.6 million population $(13.1 \%$ of the national population), to examine updated statistics in the incidence of HCC and ICC overall, by sex, area, and age group. We further examined the trends of HCC and ICC incidence from 2006 through 2015, and compared these estimates between China and the United States. A better understanding of patterns and trends of HCC and ICC incidence may provide scientific basis on the prevention and control of liver cancer. We present the following article in accordance with the STROBE reporting checklist (available at https://hbsn.amegroups.com/article/ view/10.21037/hbsn-21-75/rc).

\section{Methods}

\section{Data sources}

Data on liver cancer incidence in China were obtained from National Central Cancer Registry (NCCR), which is the sole national agency with the mandate to oversee national population-based cancer statistics in China (11). NCCR is responsible for the collection, management, analysis and publication of nationwide cancer registry data. Based on the criteria of Chinese Guideline for Cancer Registration (12) and International Agency for Research on Cancer/International Association of cancer registries (IARC/IACR) data-quality criteria (13), we checked and evaluated the cancer data by indicators, such as mortality to incidence $(\mathrm{M} / \mathrm{I})$ ratio, the percentage of cases morphologically verified (MV\%), the percentage of death certificate-only cases (DCO\%), and the percentage of cancer with unknown histological subtypes (Table S1). Registries with ten consecutive years of data which met the quality were included in the trend analyses.

To estimate the incidence of HCC and ICC in China in 2015, we used the most recent data from populationbased cancer registries of China. Of 501 cancer registries that submitted cancer registration data, we included qualified 188 local population-based cancer registries, covering about 180.6 million people ( $13.1 \%$ of the national population). The 188 qualified registries (61 in urban areas, 127 in rural areas) covered 27 provinces from seven different geographical areas of China. The distribution and population coverage of each cancer registry were shown in Figure S1. Twenty-two cancer registries, which provided 
a population coverage of about 46.6 million, had qualified data during 2006-2015 for the trend analyses. Among them, half of the cancer registries are certified by the IARC (2), the other half of the cancer registries are certified by the NCCR. In this study, we defined liver cancer based on the International Classification of Disease for Oncology (ICD-O-3) classification. HCC classification was based on: topography code of C22.0 with morphology code of 8170 8175 (14). We defined ICC based on the following criteria: topography code of C22.0 with morphology code of 8140, $8160,8161,8162,8480,8481,8500$; topography code of C22.1 with morphology code of 8000, 8010, 8020, 8140, $8160,8161,8162,8480,8481,8500$ (15).

National population data were obtained from the National Bureau of Statistics of China (16). Local cancer registries provided population data in the respective areas to the NCCR. The population denominators in each registry were from local Statistical Bureaus, Public Security Bureaus, or estimates based on national census data. Incidence data in the United States was obtained from the National Cancer Institute's Surveillance, Epidemiology, and End Results (SEER) program. We used data from 18 populationbased registries for trend analysis, covering approximately $27.8 \%$ of the United States population (17). The study was conducted in accordance with the Declaration of Helsinki (as revised in 2013). The study was approved by the ethics committee of National Cancer Center/Cancer Hospital, Chinese Academy of Medical Sciences and Peking Union Medical College (18-016/1645).

\section{Multiple imputation method}

Given that $50.8 \%$ of liver cancer cases were present with unknown subtype (C22, 8000-8005), we used multiple imputation with chained equations to impute liver cancer cases with unknown subtype. We assumed that cases with unknown histology were missing at random (18). The variables which entered the multiple imputation were age, year at diagnosis, sex, and area of residence (urban and rural area), because they were associated with the distribution of liver cancer subtype and missingness of histology $(19,20)$. We imputed 50 completed datasets and combined these 50 estimates and standard errors (SEs) based on Rubin's rule (21). We further calculated the $95 \%$ confidence interval (CI) of the incidence rates using the combined SEs. To check for multicollinearity, we calculated variation inflation factors (VIF) and no serious multicollinearity (VIF less than 5) was seen. Under the assumption that the factors were independently associated with distribution of liver cancer subtype or missingness of liver cancer subtype, we did not include interactions in multiple imputation analysis.

\section{Statistical analysis}

We used the imputed datasets to estimate the incidence of HCC and ICC, overall, by sex, area, and age group. We calculated the age-standardized rates (ASRs) of incidence based on world Segi's population (22). We examined the temporal trends of HCC and ICC incidence from 2006 to 2015 in China using a Log-linear model through Joinpoint regression program, version 4.8 (23). We restricted to a maximum of three joinpoints in all models. Trends were expressed as annual percentage change (APC), average annual percentage change (AAPC), and the $Z$ test was used to assess whether the APC or AAPC was statistically different from zero. $\mathrm{P}$ value less than 0.05 was considered significant. To compare the trends in HCC and ICC incidence between the United States and China, we used SEER*Stat developed by National Cancer Institute to analyze the incidence trends of ASR of HCC and ICC during 2006-2015 in the United States, based on SEER database.

In sensitivity analysis, we estimated trends of HCC and ICC incidence in China using the proportion of HCC and ICC in complete datasets of 22 cancer registries with known liver cancer subtype. We performed data analysis using SAS, version 9.4 (SAS Institute, Cary, NC). Multiple imputation and figures were performed using $\mathrm{R}$, version 4.0.2 (R Core Team, Vienna, Austria).

\section{Results}

In China, the estimated incidence rates and the number of new cases for HCC and ICC in 2015 by sex and area are presented in Table 1. There were about 301,500 and 61,900 newly diagnosed HCC and ICC in 2015, respectively. The ASRs of HCC and ICC incidence were 13.7 per 100,000 and 2.7 per 100,000, respectively. For both HCC and ICC, the ASRs of incidence were higher in males than in females (HCC 21.5 per 100,000 vs. 5.9 per 100,000; ICC 3.5 per $100,000 v s .1 .8$ per 100,000). By area, the ASRs for both HCC and ICC were higher in rural areas than in urban areas (HCC 16.4 per 100,000 vs. 11.8 per 100,000; ICC 2.8 per 100,000 vs. 2.6 per 100,000). For both subtypes, the age-specific incidence rates increased with age (Figure 1).

From 2006 to 2015, the ASRs of HCC incidence in 
Table 1 Estimated incidence rates and estimated new cases for HCC and ICC in China, 2015

\begin{tabular}{|c|c|c|c|c|c|c|c|}
\hline Areas & Sex & \multicolumn{3}{|c|}{$\mathrm{HCC}$} & \multicolumn{3}{|c|}{ ICC } \\
\hline \multirow[t]{2}{*}{ All areas } & Total & $301.5(288.9,314.1)$ & $21.9(21.0,22.9)$ & $13.7(13.0,14.5)$ & $61.9(56.2,67.6)$ & $4.5(4.1,4.9)$ & $2.7(2.4,3.0)$ \\
\hline & Male & $232.7(224.7,240.6)$ & $33.0(31.9,34.2)$ & $21.5(20.6,22.4)$ & $39.2(35.9,42.4)$ & $5.6(5.1,6.0)$ & $3.5(3.1,3.9)$ \\
\hline \multirow[t]{3}{*}{ Urban areas } & Total & $152.3(145.6,159.0)$ & $19.8(18.9,20.6)$ & $11.8(11.2,12.5)$ & $35.3(32.1,38.5)$ & $4.6(4.2,5.0)$ & $2.6(2.3,2.9)$ \\
\hline & Male & $119.9(115.6,124.1)$ & $30.5(29.4,31.5)$ & $18.9(18.1,19.8)$ & $22.5(20.7,24.4)$ & $5.7(5.3,6.2)$ & $3.4(3.0,3.8)$ \\
\hline & Female & $32.5(30.3,34.6)$ & $8.6(8.0,9.2)$ & $4.7(4.2,5.1)$ & $12.8(11.4,14.1)$ & $3.4(3.0,3.7)$ & $1.7(1.5,2.0)$ \\
\hline Rural areas & Total & $149.2(143.3,155.1)$ & $24.7(23.7,25.7)$ & $16.4(15.6,17.2)$ & $26.6(24.1,29.0)$ & $4.4(4.0,4.8)$ & $2.8(2.5,3.2)$ \\
\hline
\end{tabular}

ASR world: age-standardized incidence rates based on world segi's standard population. HCC, hepatocellular carcinoma; ICC, intrahepatic cholangiocarcinoma; $\mathrm{Cl}$, confidence interval.
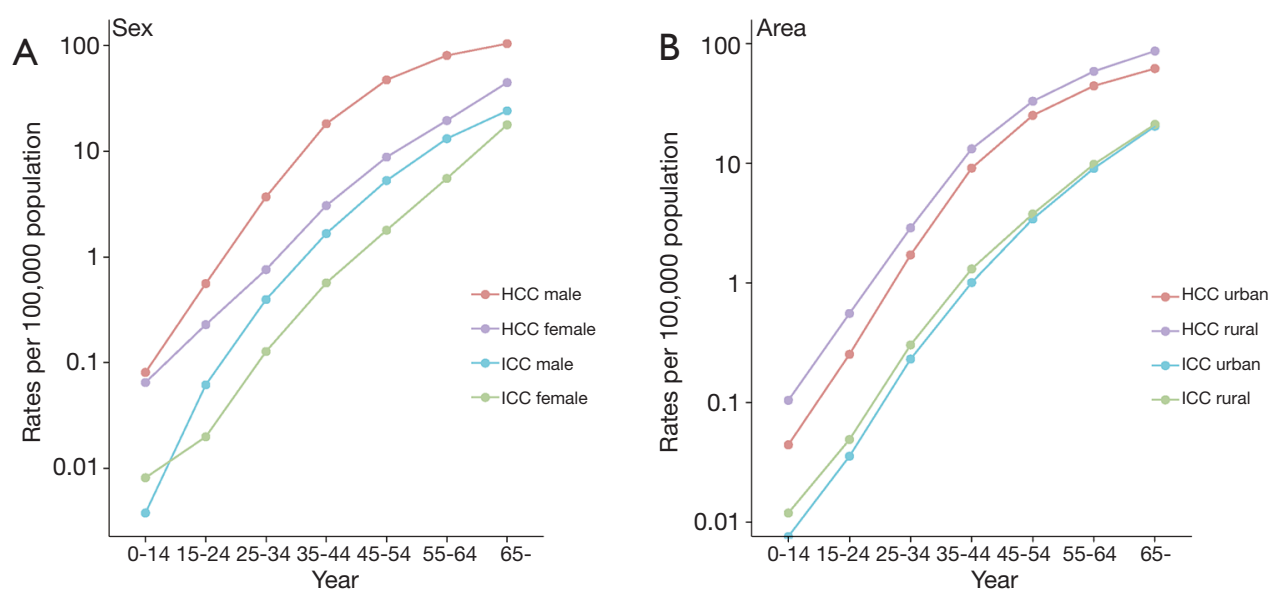

Figure 1 Age-specific incidence for HCC and ICC in China by sex and geographic area. HCC, hepatocellular carcinoma; ICC, intrahepatic cholangiocarcinoma.

22 registries of China decreased by $3.9 \%$ per year $(95 \%$ CI: $-4.7 \%$ to $-3.1 \%$ ) (Table 2, Figure 2). Especially, from 2006-2010 to 2011-2015, the ASR of HCC incidence decreased from 14.0 per 100,000 to 11.4 per 100,000 in 22 registries (Table S2). The age-specific incidence of HCC showed significant decreases in all age groups, with the sharpest decrease in the age group of $0-14$ years (AAPC: $-17.8 \%, 95 \%$ CI: $-29.3 \%$ to $-4.5 \%$ ) (Table 2). From 2006-2010 to 2011-2015, the crude incidence of HCC for subjects age $0-14$ decreased from 1.4 per million to 0.7 per million (Table S2). By sex, both males and females showed decreasing trends of HCC incidence with AAPC $-3.7 \%$ (95\% CI: $-4.4 \%$ to $-3.1 \%$ ) and $-4.1 \%$ (95\% CI: $-6.1 \%$ to $-2.1 \%$ ), respectively (Table 2, Figure 3). The HCC incidence declined by $4.3 \%$ in urban areas (95\% CI: $-5.1 \%$ to $-3.5 \%$ ) and $2.9 \%$ in rural areas (95\% CI: $-4.1 \%$ to $-1.6 \%$ ) (Table 2, Figure 4).

For ICC, the ASRs of incidence were 2.0 per 100,000 in 2006-2010 and 2.2 per 100,000 in 2011-2015 respectively (Table S3). The ASRs of overall incidence showed non- 
Table 2 Trend analysis for incidence of HCC overall, by age group, sex and area in China, 2006-2015

\begin{tabular}{|c|c|c|c|c|c|}
\hline Group & Segment1 & APC (95\% Cl) & Segment2 & APC (95\% Cl) & AAPC $(95 \% \mathrm{Cl})$ \\
\hline \multicolumn{6}{|c|}{ Age group } \\
\hline $0-14$ & 2006-2015 & $-17.8^{\star}(-29.3,-4.5)$ & & & $-17.8^{*}(-29.3,-4.5)$ \\
\hline $15-24$ & 2006-2010 & $3.8(-9.1,18.6)$ & 2010-2015 & $-15.6^{\star}(-23.2,-7.3)$ & $-7.5^{\star}(-12.9,-1.7)$ \\
\hline $35-44$ & 2006-2015 & $-4.7^{\star}(-5.9,-3.4)$ & & & $-4.7^{\star}(-5.9,-3.4)$ \\
\hline $45-54$ & 2006-2008 & $0.5(-4.8,6.1)$ & 2008-2015 & $-4.9^{*}(-5.6,-4.2)$ & $-3.7^{\star}(-4.7,-2.8)$ \\
\hline $55-64$ & 2006-2015 & $-3.4^{\star}(-4.1,-2.7)$ & & & $-3.4^{\star}(-4.1,-2.7)$ \\
\hline$\geq 65$ & 2006-2008 & $3.5(-3.5,11.0)$ & 2008-2015 & $-4.3^{\star}(-5.2,-3.4)$ & $-2.6^{\star}(-3.9,-1.4)$ \\
\hline Female & $2006-2008$ & $2.9(-7.9,15.0)$ & 2008-2015 & $-6.0^{\star}(-7.4,-4.6)$ & $-4.1^{\star}(-6.1,-2.1)$ \\
\hline \multicolumn{6}{|l|}{ Area } \\
\hline Urban & 2006-2015 & $-4.3^{*}(-5.1,-3.5)$ & & & $-4.3^{\star}(-5.1,-3.5)$ \\
\hline Rural & 2006-2015 & $-2.9^{\star}(-4.1,-1.6)$ & & & $-2.9^{\star}(-4.1,-1.6)$ \\
\hline
\end{tabular}

*, the APC or AAPC is significantly different from zero $(\mathrm{P}<0.05)$. $\mathrm{HCC}$, hepatocellular carcinoma; APC, annual percentage change; $\mathrm{Cl}$, confidence interval; AAPC, average annual percentage change.
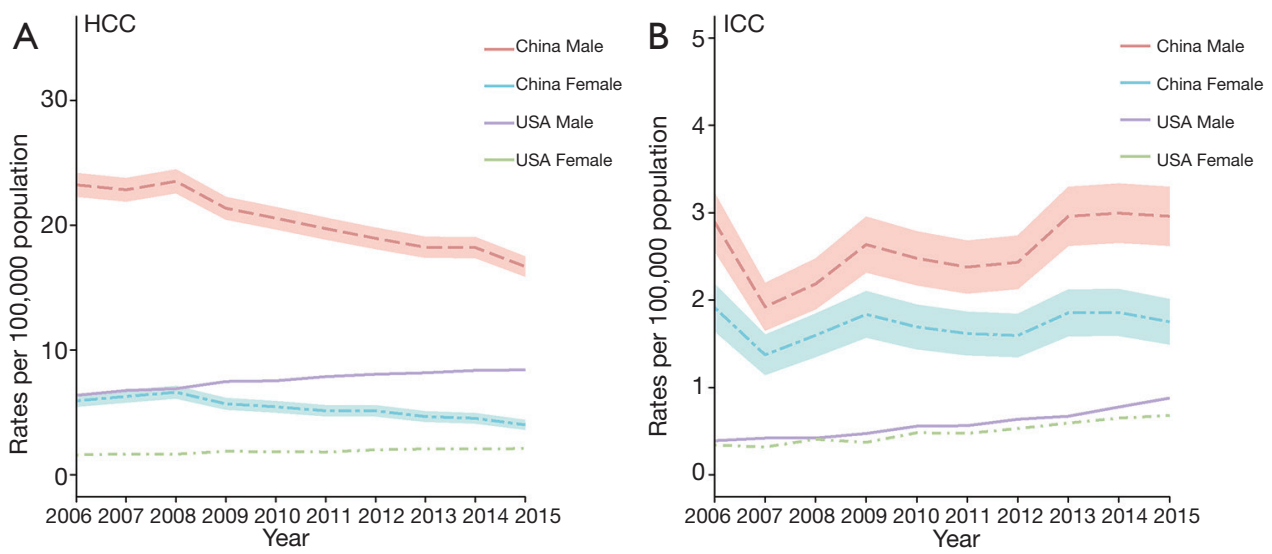

Figure 2 Trends in age-standardized incidence for HCC and ICC between China and USA, 2006-2015. HCC, hepatocellular carcinoma; ICC, intrahepatic cholangiocarcinoma.

significant increase during 2006-2015 in China (AAPC: $2.1 \%, 95 \%$ CI: $-0.9 \%$ to $5.1 \%)$. However, we observed a significant increase of ICC incidence in individuals over 65 years old (AAPC: $3.1 \%$, 95\% CI: $0.4 \%$ to $5.9 \%$ ) (Table 3). Trends of ICC incidence were further analyzed by sex and by area. Similar stable trends were shown in males, females, in urban areas and rural areas (Figures 3,4).

In the United States, the ASR for HCC incidence increased from $3.9 / 100,000$ in 2006 to $5.1 / 100,000$ in 2015, representing an AAPC of $3.3 \%$ (95\% CI: $2.6 \%$ to $4.1 \%$ ). The ASR for ICC incidence increased from $0.36 / 100,000$ in 2006 to $0.77 / 100,000$ in 2015, representing an AAPC of $9.2 \%$ 

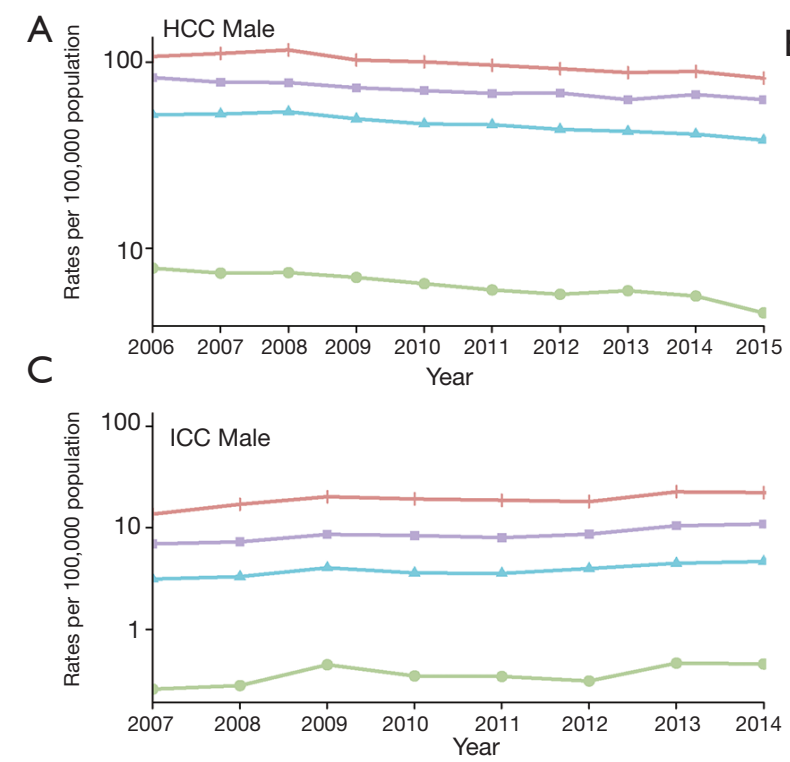

\section{B}
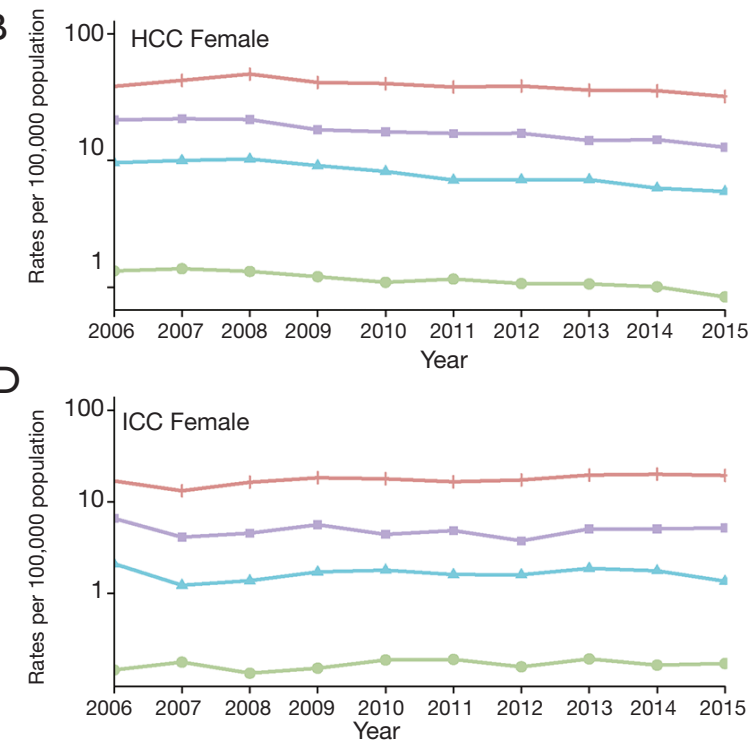

Figure 3 Trends in age-specific incidence for HCC and ICC after multiple imputation in China, 2006-2015, by sex. HCC, hepatocellular carcinoma; ICC, intrahepatic cholangiocarcinoma.

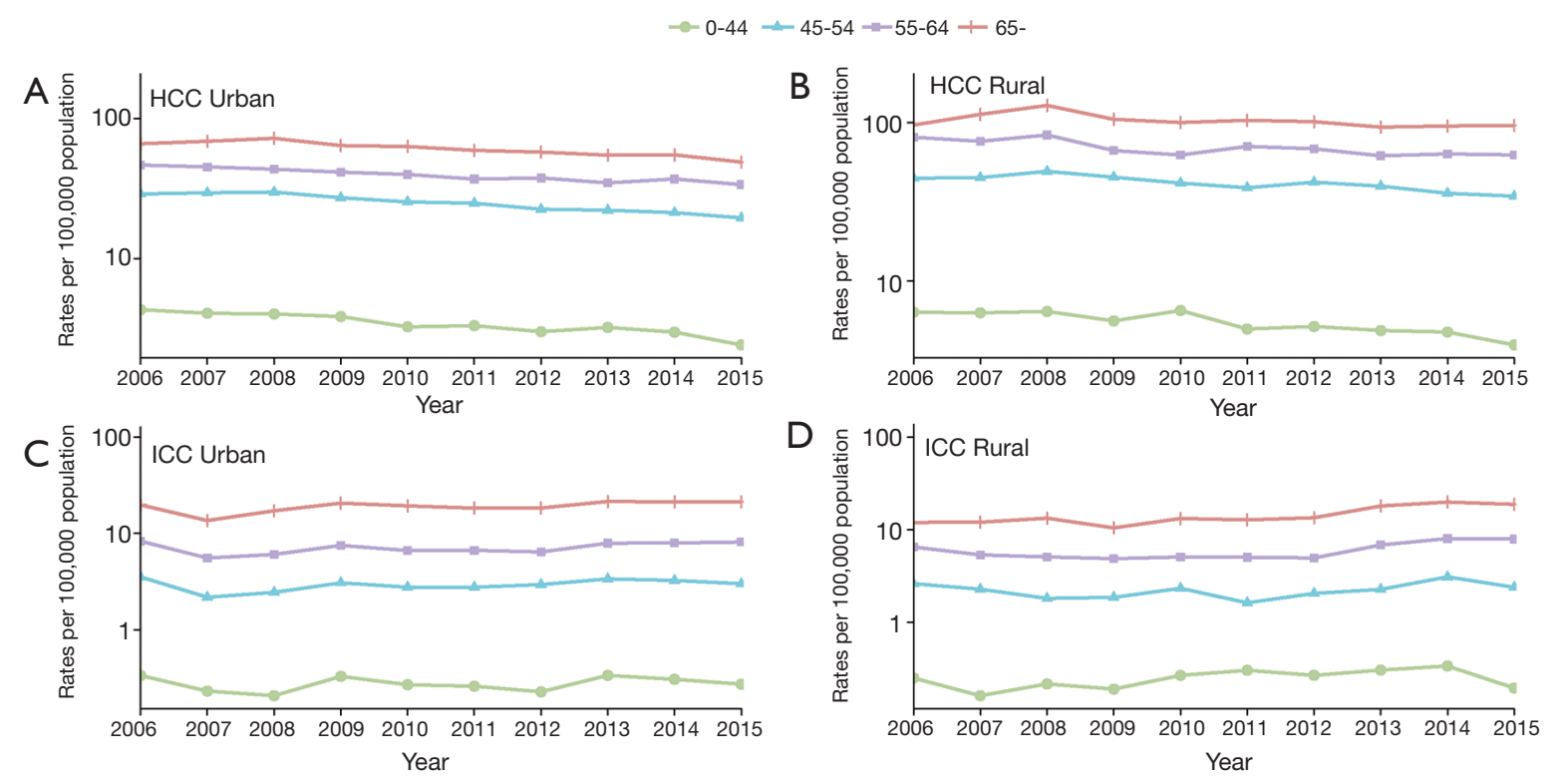

Figure 4 Trends in age-specific incidence for HCC and ICC after multiple imputation in China, 2006-2015, by area. HCC, hepatocellular carcinoma; ICC, intrahepatic cholangiocarcinoma.

(95\% CI: $8.1 \%$ to $10.3 \%$ ) in the United States (Figure 2).

Sensitivity analyses showed similar declining trends in ASRs of incidence and age-specific incidence for HCC (Table S4). While the overall ASRs of incidence for ICC increased significantly with AAPC of $3.1 \%$ (Table S4).

\section{Discussion}

Using the most updated cancer registration data in China, we provided comprehensive information on the nationwide incidence of HCC and ICC in China during 2006-2015. Our results showed that in China, the burden of HCC 
Table 3 Trend analysis for incidence of ICC overall, by age group, sex and area in China, 2006-2015

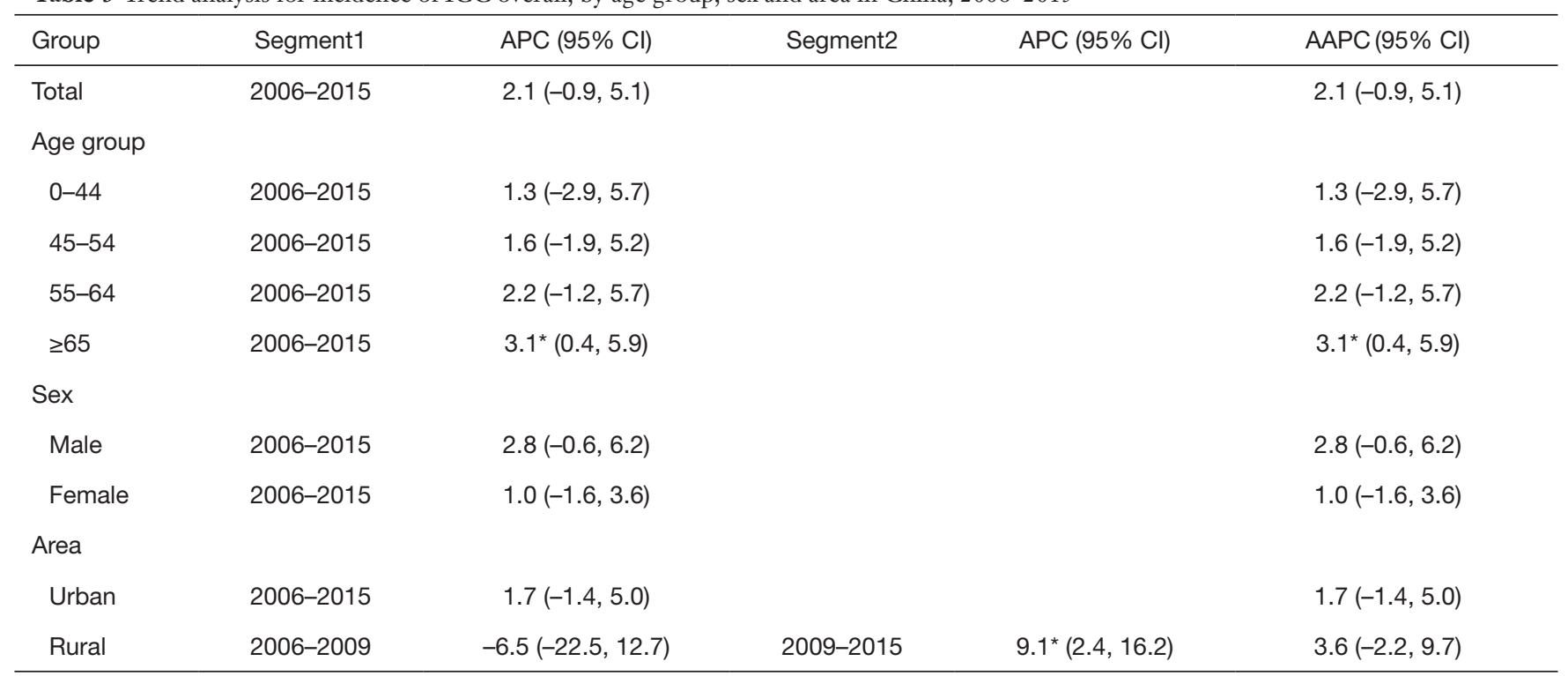

*, the APC or AAPC is significantly different from zero $(\mathrm{P}<0.05)$. ICC, intrahepatic cholangiocarcinoma; APC, annual percentage change; $\mathrm{Cl}$, confidence interval; AAPC, average annual percentage change.

remains high, and that disparities in burden of HCC persist across gender. In China, males are more likely to develop HCC than females. Hormonal factors may partially explain the sex differences in incidence $(24,25)$. Consistent with this hypothesis, the national hepatitis serosurvey conducted in 2006 showed that males had higher HBV surface antigen (HBsAg) seropositivity than females (8.6\% vs. 5.7\%) (26). Similarly, the prevalence of anti-HCV seropositivity was higher in males than in females $(0.5 \%$ vs. $0.4 \%)$ (27). The synergistic action of sex hormones and of immune responses, together with viral factors may be associated with disparities in the outcome and progression of HBV/ $\mathrm{HCV}$ infection (28). Meanwhile, potential differences of unhealthy lifestyle risk factors may also contribute to the sex disparities in HCC incidence. For instance, the prevalence of unhealthy drinking in males and females was $7.9 \%$ and $3.3 \%$, respectively (29).

We found that rural residents had higher incidence of HCC compared to their urban counterparts. Many factors likely contribute to this geographic disparity, but the varying prevalence of $\mathrm{HBV}$ and $\mathrm{HCV}$ in different areas likely plays dominant roles (30-32). In 2006, the HBsAg prevalence was higher in rural areas (7.3\%) than in urban areas (6.8\%). Especially, the proportion of HBsAg seropositivity was 8.3\% in western areas, $6.7 \%$ in central areas and $6.5 \%$ in eastern areas (26). The prevalence of $\mathrm{HCV}$ infection was higher in North China (0.5\%) than in South China (0.3\%) (27).
We found a significantly decreasing trend of HCC incidence in China, with the sharpest decrease in population less than 14 years. HBV infection has been regarded as the major cause of liver cancer (33). It was estimated that about $76 \%$ of HCC cases were HBsAg-positive in China mainland (31). The HBV vaccine was firstly recommended for routine vaccination of infants by Ministry of Health in China in 1992 (3). Then China made the HBV vaccination to all children at no cost in $2002(34,35)$. With the support of national financial funds, the neonatal Hepatitis B vaccination rates increased from $30.0 \%$ in 1992 to $99.6 \%$ in 2015 (36). The success of HBV vaccination has been shown to prevent liver cancer in children previously $(37,38)$. Our results may further support the contribution of $\mathrm{HBV}$ vaccination to $\mathrm{HCC}$ incidence decrease in China. Meanwhile, we observed significantly declining trends of HCC incidence in elderly population who did not receive neonatally $\mathrm{HBV}$ vaccination. Therefore, other factors may also contribute to the decrease of HCC incidence, including a reduction in the consumption of aflatoxins-contaminated food and improved quality of drinking water by removing cyanotoxins from water sources (39-41). This finding is supported by a previous study from Qidong in China, which had high liver cancer incidence partly because of dietary exposure to aflatoxin. After interventions in 1980s to reduce dietary aflatoxin, aflatoxin-albumin adduct levels have decreased by 40 -folds and liver cancer incidence has 
decreased by up to 14 -folds (42).

In China, ICC incidence rates were lower than that of HCC, which was a general situation in most countries. Notable exception was Thailand, where the rate of ICC was consistently similar to HCC (8). Similar to HCC, ICC presented sex and geographic disparities, as males and residents in rural areas had higher incidence than females and individuals in urban areas. Contrary to declining trend of HCC incidence, the incidence rate of ICC did not show a decrease in China during the past few years. We even observed an increasing trend of ICC in the elderly population. These results suggest potential etiological differences between HCC and ICC. For instance, primary sclerosing cholangitis and choledocholithiasis are the established risk factors for ICC. Meanwhile, the same risk factors such as HBV infection could be related to both cancers but pose a much greater risk for HCC than ICC. Similar studies raise the concern of rising incidence of ICC worldwide $(43,44)$. ICC is a rare cancer with dismal prognosis. A further investigation is warranted to explore the relative contribution of multiple potential risk factors in the future.

The etiology of liver cancer is multifactorial. China and the United States have varying distribution of potential risk factors. For instance, in 2016, the prevalence of HBV seropositivity in China and in the United States was 3.5\% and $0.3 \%$, respectively $(45,46)$. The estimated prevalence of non-alcoholic fatty liver disease (NAFLD) in China (17.6\%) was lower than the United States (26.3\%) in 2016 (47). And prevalence of obesity in China was lower than that in the United States (male: $5.0 \%$ vs. $30.7 \%$; female $5.5 \%$ vs. $35.5 \%)(48)$.

Our results showed that, although HCC incidence in the United States is lower than in China, it has increased by $30 \%$ in the United States over the past ten years. Much of this might be explained by the differences in the attributable risk factors of HCC between the two countries. In China, a decline in the prevalence of $\mathrm{HBV}$ has been attributed to the $\mathrm{HBV}$ vaccination (10). By contrast, the prevalence of $\mathrm{HCV}$, which was the predominant cause of HCC in the United States, has been increasing (49). The number of new cases of $\mathrm{HCV}$ infection in United States increased from 10,000 per year in 2005 to 40,000 per year in 2016 (50). In the United States, it is estimated that NAFLD is becoming an important cause of HCC, and these rates are increasing by approximately $10 \%$ per year (51). Other possible explanations for the increase in HCC rates in the United States include better diagnosis for HCC, better survival of cirrhotic patients and possibly as well as increased rates of diabetes and obesity. In the United States, the incidence rate of ICC has doubled from 2006 to 2015. Factors that may have contributed to the increase include the increase in the prevalence of unhealthy lifestyle and the improvement in disease awareness, detection services, and data completeness. Some risk factors for ICC, such as diabetes, although weak, are increasing globally and may contribute to the rising rates of ICC in the United States.

Our study for the first time provides the most updated and comprehensive information on nationwide incidence of HCC and ICC in China, using data from 188 cancer registries, covering 180.6 million population (13.1\% of the national population), which were the largest and best available population-based estimates in China. As the primary source of cancer statistics for the Chinese government, it is also the updated largest effort undertaken by the NCCR of China. This finding may not only provide scientific basis for precise control of HCC and ICC in China, but also may support for generating etiological hypotheses and exploring potentially risk factors. However, the study has several limitations. First, the percentage of cases with unknown liver cancer subtype was $50.8 \%$ in our study. Population-based data of liver cancer usually has a high percentage of missing histological diagnosis because liver is a deep organ and the diagnosis of liver cancer by histopathological and/or cytological confirmation would only be made in those with a good performance status. Moreover, if the patients are present with the disease at late stage and the aim of treatment by physicians is just for palliation, investigation for specific histological type is not necessary. Thus, we used multiple imputation methods to impute the missing data with unknown liver cancer subtype. Previous study from Thailand with $60-67 \%$ of missing histological diagnosis for liver cancer applied the same approach for the missing data (14). Sensitivity analysis without multiple imputation showed similar trends of HCC reduction and ICC increase in the elderly population ( $>65$ years). Second, although we used the largest population registries' data to estimate the national incidence, the covered individuals still represent less than one-fifth of the total Chinese population only. There remains an unknown level of uncertainties in these estimates. NCCR of China will take more extensive efforts to improve the quality of cancer data and population coverage of cancer registration. In particular, China has established a systematic plan to set up cancer registration framework in each county of China up to 2022 (52). Third, exploring possible causes of HCC 
and ICC will be useful to understand the disparities of HCC and ICC across different population. The NCCR does not provide nationwide data on cancer risk factors, we therefore cannot determine specific causes for observed trends. Using a prospective design to collect both information on risk factors and liver cancer outcome will be beneficial to understand more deeply between the risk factors and HCC/ICC incidence. Fourth, information of staging and survival will be important to understand the diagnostic and prognosis of HCC and ICC. Since 2015, China has invested stable funding in population-based survival investigations. We may further compare the stage and survival of HCC and ICC between China and the United States in the future.

In summary, this is the first study providing comprehensive nationwide incidence of HCC and ICC in China. We observed a significantly pronounced decrease in the incidence of HCC from 2006 to 2015. Our results may further support contribution of $\mathrm{HBV}$ vaccination to the sharp decrease of HCC incidence in the Chinese young population. Meanwhile, the incidence of ICC in population who were 65 years and above is still on the rise. Given that China still has 86 million cases with $\mathrm{HBsAg}$ positivity, an estimated 8.9 million people living with chronic $\mathrm{HCV}$ infection (53), and the aging population is still growing (54), the burden of liver cancer will continue to be heavy. Therefore, liver cancer is still a priority when allocating cancer control resources in the country. In the United States, both HCC and ICC are on the rise. Healthy lifestyle promotion and infection control are especially needed for future liver cancer control and prevention for both countries.

\section{Acknowledgments}

We express deep gratitude to all the local cancer registry staffs in China for contributing to the data collection, validation, and routine analyses.

Funding: The funding resources of this study were National Key R\&D Program of China (2016YFC1302502, 2017YFC0908103) and Major State Basic Innovation Program of the Chinese Academy of Medical Sciences (2019-I2M-2-004).

\section{Footnote}

Reporting Checklist: The authors have completed the STROBE reporting checklist. Available at https://hbsn. amegroups.com/article/view/10.21037/hbsn-21-75/rc
Data Sharing Statement: Available at https://hbsn. amegroups.com/article/view/10.21037/hbsn-21-75/dss

Conflicts of Interest: All authors have completed the ICMJE uniform disclosure form (available at https://hbsn. amegroups.com/article/view/10.21037/hbsn-21-75/coif). The authors have no conflicts of interest to declare.

Etbical Statement: The authors are accountable for all aspects of the work in ensuring that questions related to the accuracy or integrity of any part of the work are appropriately investigated and resolved. The study was conducted in accordance with the Declaration of Helsinki (as revised in 2013). The study was approved by the ethics committee of National Cancer Center/Cancer Hospital, Chinese Academy of Medical Sciences and Peking Union Medical College (18-016/1645).

Open Access Statement: This is an Open Access article distributed in accordance with the Creative Commons Attribution-NonCommercial-NoDerivs 4.0 International License (CC BY-NC-ND 4.0), which permits the noncommercial replication and distribution of the article with the strict proviso that no changes or edits are made and the original work is properly cited (including links to both the formal publication through the relevant DOI and the license). See: https://creativecommons.org/licenses/by-nc-nd/4.0/.

\section{References}

1. Sung H, Ferlay J, Siegel RL, et al. Global Cancer Statistics 2020: GLOBOCAN Estimates of Incidence and Mortality Worldwide for 36 Cancers in 185 Countries. CA Cancer J Clin 2021;71:209-49.

2. Chen $\mathrm{W}$, Zheng R, Baade PD, et al. Cancer statistics in China, 2015. CA Cancer J Clin 2016;66:115-32.

3. Zheng R, Qu C, Zhang S, et al. Liver cancer incidence and mortality in China: Temporal trends and projections to 2030. Chin J Cancer Res 2018;30:571-9.

4. Massarweh NN, El-Serag HB. Epidemiology of Hepatocellular Carcinoma and Intrahepatic Cholangiocarcinoma. Cancer Control 2017;24:1073274817729245.

5. WHO. International Agency for Research on Cancer. Known causes and prevention of human cancer by organ site. Accessed August 15, 2020. Available online: https:// monographs.iarc.fr/

6. Singal AG, El-Serag HB. Hepatocellular Carcinoma From Epidemiology to Prevention: Translating Knowledge into 
Practice. Clin Gastroenterol Hepatol 2015;13:2140-51.

7. Llovet JM, Zucman-Rossi J, Pikarsky E, et al. Hepatocellular carcinoma. Nat Rev Dis Primers 2016;2:16018.

8. Petrick JL, Braunlin M, Laversanne M, et al. International trends in liver cancer incidence, overall and by histologic subtype, 1978-2007. Int J Cancer 2016;139:1534-45.

9. Dasgupta P, Henshaw C, Youlden DR, et al. Global Trends in Incidence Rates of Primary Adult Liver Cancers: A Systematic Review and Meta-Analysis. Front Oncol 2020;10:171.

10. Bray F, Ferlay J, Soerjomataram I, et al. Global cancer statistics 2018: GLOBOCAN estimates of incidence and mortality worldwide for 36 cancers in 185 countries. CA Cancer J Clin 2018;68:394-424.

11. Wei W, Zeng H, Zheng R, et al. Cancer registration in China and its role in cancer prevention and control. Lancet Oncol 2020;21:e342-9.

12. National Cancer Center, Disease Prevention and Control Bureau, Ministry of Health. Chinese Cancer Registry Annual Report 2012. Beijing, China: Ministry of Health; 2012.

13. Ferlay J BC, Whelan S, Parkin DM. Check and Conversion Programs for Cancer Registries (IARC/IACR Tools for Cancer Registries). IARC Technical Report No 42 Lyon, France: IARC Press 2005.

14. Yeesoonsang S, Bilheem S, McNeil E, et al. Estimation of the Incidence of Hepatocellular Carcinoma and Cholangiocarcinoma in Songkhla, Thailand, 1989-2013, Using Multiple Imputation Method. Cancer Res Treat 2017;49:54-60.

15. Tyson GL, Ilyas JA, Duan Z, et al. Secular trends in the incidence of cholangiocarcinoma in the USA and the impact of misclassification. Dig Dis Sci 2014;59:3103-10.

16. National Bureau of Statistics of China. China statistical yearbook 2015. Accessed July 24, 2020. Available online: http://www.stats.gov.cn/tjsj/ndsj/2015/indexeh.htm

17. Surveillance, Epidemiology, and End Results (SEER) Program. SEER*Stat Database: Incidence - SEER Research Data, 18 Registries, Nov 2019 Sub (2000-2017). Available online: https://seer.cancer.gov/data-software/ documentation/seerstat/nov2019/

18. White IR, Royston P, Wood AM. Multiple imputation using chained equations: Issues and guidance for practice. Stat Med 2011;30:377-99.

19. Howlader N, Noone AM, Yu M, et al. Use of imputed population-based cancer registry data as a method of accounting for missing information: application to estrogen receptor status for breast cancer. Am J Epidemiol
2012;176:347-56.

20. Azur MJ, Stuart EA, Frangakis C, et al. Multiple imputation by chained equations: what is it and how does it work? Int J Methods Psychiatr Res 2011;20:40-9.

21. Little RJA, Rubin DB. Statistical analysis with missing data. Cambridge (MA): John Wiley \& Sons, 2019.

22. Bray F, Guilloux A, Sankila R, et al. Practical implications of imposing a new world standard population. Cancer Causes Control 2002;13:175-82.

23. Kim HJ, Fay MP, Feuer EJ, et al. Permutation tests for joinpoint regression with applications to cancer rates. Stat Med 2000;19:335-51.

24. Naugler WE, Sakurai T, Kim S, et al. Gender disparity in liver cancer due to sex differences in MyD88-dependent IL-6 production. Science 2007;317:121-4.

25. Petrick JL, Florio AA, Zhang X, et al. Associations Between Prediagnostic Concentrations of Circulating Sex Steroid Hormones and Liver Cancer Among Postmenopausal Women. Hepatology 2020;72:535-47.

26. Liang X, Bi S, Yang W, et al. Reprint of: Epidemiological serosurvey of Hepatitis B in China--declining HBV prevalence due to Hepatitis B vaccination. Vaccine 2013;31 Suppl 9:J21-8.

27. Chen YS, Li L, Cui FQ, et al. A sero-epidemiological study on hepatitis $\mathrm{C}$ in China. Zhonghua Liu Xing Bing Xue Za Zhi 2011;32:888-91.

28. Ruggieri A, Gagliardi MC, Anticoli S. Sex-Dependent Outcome of Hepatitis B and C Viruses Infections: Synergy of Sex Hormones and Immune Responses? Front Immunol 2018;9:2302.

29. Li YR, Wang J, Zhao LY, et al. The drinking status and associated factors in adults in China. Zhonghua Liu Xing Bing Xue Za Zhi 2018;39:898-903.

30. Islami F, Chen W, Yu XQ, et al. Cancer deaths and cases attributable to lifestyle factors and infections in China, 2013. Ann Oncol 2017;28:2567-74.

31. de Martel C, Maucort-Boulch D, Plummer M, et al. World-wide relative contribution of hepatitis $\mathrm{B}$ and $\mathrm{C}$ viruses in hepatocellular carcinoma. Hepatology 2015;62:1190-200.

32. Wang LJ, Yin P, Liu YN, et al. Disease burden of liver cancer in the Chinese population, in 1990 and 2013. Zhonghua Liu Xing Bing Xue Za Zhi 2016;37:758-62.

33. Chen W, Xia C, Zheng R, et al. Disparities by province, age, and sex in site-specific cancer burden attributable to 23 potentially modifiable risk factors in China: a comparative risk assessment. Lancet Glob Health 2019; 7:e257-69. 
34. Sun Z, Ming L, Zhu X, et al. Prevention and control of hepatitis B in China. J Med Virol 2002;67:447-50.

35. Qu C, Duan Z, Chen K, et al. Reducing liver cancer risk beginning at birth: experiences of preventing chronic hepatitis B virus infection in China. Hepatoma Research 2017;3:228-40.

36. Liu J, Liang W, Jing W, et al. Countdown to 2030: eliminating hepatitis B disease, China. Bull World Health Organ 2019;97:230-8.

37. Li RC, Yang JY, Gong J, et al. Efficacy of hepatitis $B$ vaccination on hepatitis $B$ prevention and on hepatocellular carcinoma. Zhonghua Liu Xing Bing Xue Za Zhi 2004;25:385-7.

38. Chang MH, Chen CJ, Lai MS, et al. Universal hepatitis B vaccination in Taiwan and the incidence of hepatocellular carcinoma in children. Taiwan Childhood Hepatoma Study Group. N Engl J Med 1997;336:1855-9.

39. Chen J, Zhu J, Wang G, et al. Qidong: a crucible for studies on liver cancer etiology and prevention. Cancer Biol Med 2019;16:24-37.

40. Sun Z, Chen T, Thorgeirsson SS, et al. Dramatic reduction of liver cancer incidence in young adults: 28 year follow-up of etiological interventions in an endemic area of China. Carcinogenesis 2013;34:1800-5.

41. Ueno Y, Nagata S, Tsutsumi T, et al. Detection of microcystins, a blue-green algal hepatotoxin, in drinking water sampled in Haimen and Fusui, endemic areas of primary liver cancer in China, by highly sensitive immunoassay. Carcinogenesis 1996;17:1317-21.

42. Sun Z, Chen T, Thorgeirsson SS, et al. Dramatic reduction of liver cancer incidence in young adults: 28 year follow-up of etiological interventions in an endemic area of China. Carcinogenesis 2013;34:1800-5.

43. Antwi SO, Mousa OY, Patel T. Racial, Ethnic, and Age Disparities in Incidence and Survival of Intrahepatic Cholangiocarcinoma in the United States; 1995-2014. Ann Hepatol 2018;17:604-14.

44. Florio AA, Ferlay J, Znaor A, et al. Global trends in intrahepatic and extrahepatic cholangiocarcinoma

Cite this article as: An L, Zheng R, Zhang S, Chen R, Wang S, Sun K, Lu L, Zhang X, Zhao H, Zeng H, Wei W, He J. Hepatocellular carcinoma and intrahepatic cholangiocarcinoma incidence between 2006 and 2015 in China: estimates based on data from 188 population-based cancer registries. HepatoBiliary Surg Nutr 2023;12(1):45-55. doi: 10.21037/hbsn-21-75 incidence from 1993 to 2012. Cancer 2020;126:2666-78.

45. Le MH, Yeo YH, Cheung R, et al. Chronic Hepatitis B Prevalence Among Foreign-Born and U.S.-Born Adults in the United States, 1999-2016. Hepatology 2020;71:431-43.

46. Zhang WL, Ji ZH, Fu T, et al. Meta analysis on HBsAgpositive rate among general populations aged 1-59 years, 2007-2016, China. Zhonghua Liu Xing Bing Xue Za Zhi 2017;38:1278-84.

47. Estes C, Anstee QM, Arias-Loste MT, et al. Modeling NAFLD disease burden in China, France, Germany, Italy, Japan, Spain, United Kingdom, and United States for the period 2016-2030. J Hepatol 2018;69:896-904.

48. GBD 2015 Obesity Collaborators; Afshin A, Forouzanfar $\mathrm{MH}$, et al. Health Effects of Overweight and Obesity in 195 Countries over 25 Years. N Engl J Med 2017;377:13-27.

49. Thrift AP, El-Serag HB, Kanwal F. Global epidemiology and burden of HCV infection and HCV-related disease. Nat Rev Gastroenterol Hepatol 2017;14:122-32.

50. Jafri SM, Gordon SC. Epidemiology of Hepatitis C. Clin Liver Dis (Hoboken) 2018;12:140-2.

51. Younossi ZM, Otgonsuren M, Henry L, et al. Association of nonalcoholic fatty liver disease (NAFLD) with hepatocellular carcinoma (HCC) in the United States from 2004 to 2009. Hepatology 2015;62:1723-30.

52. The State Council of the People's Republic of China. Evaluation plan on "Healthy China" released. Accessed April 2, 2021. Available online: http:// english.gov.cn/policies/latest_releases/2019/07/15/ content_281476765919352.htm

53. Global Burden of Disease Study 2013 Collaborators. Global, regional, and national incidence, prevalence, and years lived with disability for 301 acute and chronic diseases and injuries in 188 countries, 1990-2013: a systematic analysis for the Global Burden of Disease Study 2013. Lancet 2015;386:743-800.

54. Polaris Observatory Collaborators. Global prevalence, treatment, and prevention of hepatitis $B$ virus infection in 2016: a modelling study. Lancet Gastroenterol Hepatol 2018;3:383-403. 


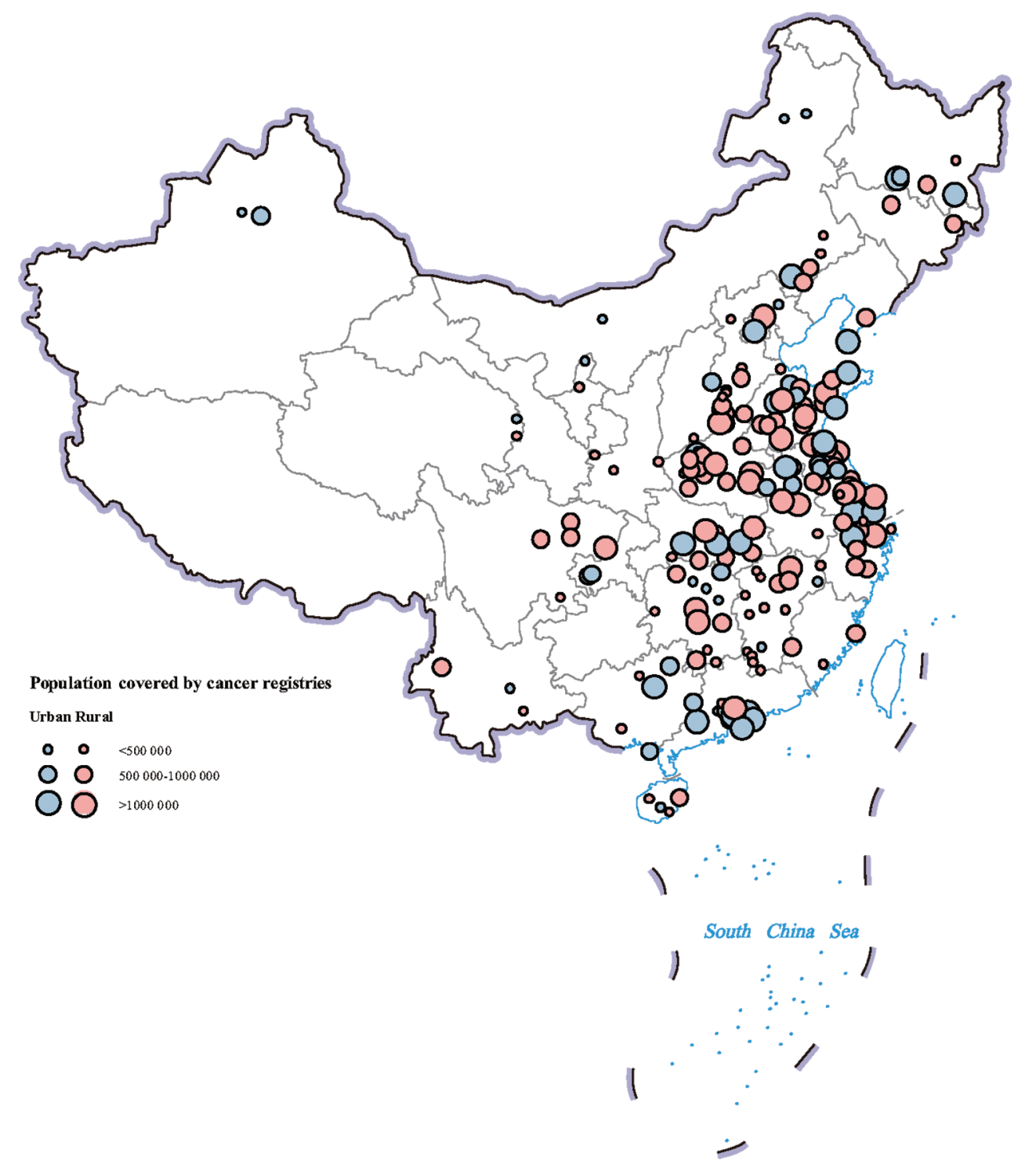

Figure S1 Distribution and population density of 188 cancer registries. 
Table S1 Indicators of data quality by area and sex for the 188 cancer registries in China

\begin{tabular}{|c|c|c|c|c|c|}
\hline Areas & Sex & $\mathrm{MV} \%$ & DCO \% & $\mathrm{M} / \mathrm{I}$ & Unknown subtype\% \\
\hline \multirow[t]{3}{*}{ All areas } & Total & 37.5 & 3.3 & 0.9 & 50.8 \\
\hline & Male & 38.1 & 3.1 & 0.9 & 50.5 \\
\hline & Female & 35.9 & 3.9 & 0.9 & 51.5 \\
\hline \multirow[t]{3}{*}{ Urban areas } & Total & 37.2 & 3.7 & 0.9 & 52.4 \\
\hline & Male & 37.6 & 3.5 & 0.9 & 52.4 \\
\hline & Female & 36.1 & 4.2 & 0.9 & 52.1 \\
\hline \multirow[t]{3}{*}{ Rural areas } & Total & 37.8 & 3.0 & 0.9 & 49.5 \\
\hline & Male & 38.5 & 2.7 & 0.9 & 49.0 \\
\hline & Female & 35.7 & 3.7 & 0.9 & 51.1 \\
\hline
\end{tabular}

$\mathrm{MV} \%$, the percentage of cases morphologically verified; DCO\%, the percentage of death certificate-only cases; M/l, mortality to incidence ratio; Unknown subtype \%, the percentage of cancer with unknown subtype.

Table S2 Estimated incidence rate of HCC in China overall, by sex and age group between 2006-2010 and 2011-2015

\begin{tabular}{|c|c|c|c|c|}
\hline \multirow{2}{*}{ Group } & \multicolumn{2}{|c|}{ 2006-2010 } & \multicolumn{2}{|c|}{ 2011-2015 } \\
\hline & Crude rate (per 100,000) & ASR World (per 100,000) & Crude rate (per 100,000$)$ & ASR World (per 100,000) \\
\hline Total & 21.7 & 14.0 & 20.5 & 11.4 \\
\hline \multicolumn{5}{|l|}{ Sex } \\
\hline Male & 33.2 & 22.2 & 31.7 & 18.3 \\
\hline Female & 10.0 & 6.0 & 9.2 & 4.7 \\
\hline \multicolumn{5}{|l|}{ Age group } \\
\hline $0-14$ & 0.14 & - & 0.07 & - \\
\hline $15-24$ & 0.4 & - & 0.3 & - \\
\hline $25-34$ & 2.7 & - & 1.8 & - \\
\hline $35-44$ & 12.5 & - & 9.7 & - \\
\hline $45-54$ & 30.5 & - & 24.7 & - \\
\hline $55-64$ & 47.5 & - & 40.2 & - \\
\hline$\geq 65$ & 72.5 & - & 60.8 & - \\
\hline
\end{tabular}

ASR world, age-standardized incidence rates based on world segi's standard population.

Table S3 Estimated incidence rate of ICC in China overall and by sex between 2006-2010 and 2011-2015

\begin{tabular}{lccccc}
\hline \multirow{2}{*}{ Group } & \multicolumn{2}{c}{$2006-2010$} & & \multicolumn{2}{c}{$2011-2015$} \\
\cline { 2 - 3 } \cline { 5 - 6 } & Crude rate (per 100,000) & ASR World (per 100,000) & & Crude rate (per 100,000) & ASR World (per 100,000) \\
\hline Total & 3.4 & 2.0 & 4.5 & 2.2 & 2.7 \\
Male & 3.7 & 2.4 & 5.1 & 3.8 & 1.7 \\
Female & 3.1 & 1.7 & 3.8 & \\
\hline
\end{tabular}

ASR world, age-standardized incidence rates based on world segi's standard population. 
Table S4 Trend analysis for incidence of HCC and ICC using dataset with known subtype in China, 2006-2015

\begin{tabular}{|c|c|c|c|c|c|c|}
\hline Type & Group & Segment1 & $\operatorname{APC}(95 \% \mathrm{Cl})$ & Segment2 & $\operatorname{APC}(95 \% \mathrm{Cl})$ & $\operatorname{AAPC}(95 \% \mathrm{Cl})$ \\
\hline \multirow{15}{*}{$\mathrm{HCC}$} & Total & 2006-2015 & $-3.9^{*}(-4.7,-3.0)$ & & & $-3.9^{*}(-4.7,-3.0)$ \\
\hline & Age group & & & & & \\
\hline & $0-14$ & 2006-2015 & $-18.3^{*}(-30.0,-4.7)$ & & & $-18.3^{*}(-30.0,-4.7)$ \\
\hline & $15-24$ & 2006-2015 & $-9.2(-18.5,1.3)$ & & & $-9.2(-18.5,1.3)$ \\
\hline & $25-34$ & 2006-2015 & $-8.9^{\star}(-11.0,-6.7)$ & & & $-8.9^{*}(-11.0,-6.7)$ \\
\hline & $35-44$ & 2006-2015 & $-3.9^{\star}(-5.9,-1.9)$ & & & $-3.9^{*}(-5.9,-1.9)$ \\
\hline & $45-54$ & 2006-2015 & $-4.8^{\star}(-5.9,-3.6)$ & & & $-4.8^{*}(-5.9,-3.6)$ \\
\hline & $55-64$ & 2006-2015 & $-3.2^{*}(-4.1,-2.2)$ & & & $-3.2^{*}(-4.1,-2.2)$ \\
\hline & $\geq 65$ & 2006-2015 & $-3.1^{*}(-4.3,-1.7)$ & & & $-3.1^{*}(-4.3,-1.7)$ \\
\hline & Sex & & & & & \\
\hline & Male & 2006-2015 & $-4.0^{\star}(-4.7,-3.2)$ & & & $-4.0^{\star}(-4.7,-3.2)$ \\
\hline & Female & $2006-2008$ & $4.9(-11.7,24.5)$ & 2008-2015 & $-4.8^{\star}(-7.0,-2.6)$ & $-2.7(-5.8,0.4)$ \\
\hline & Area & & & & & \\
\hline & Urban & 2006-2015 & $-3.9^{\star}(-5.0,-2.9)$ & & & $-3.9^{\star}(-5.0,-2.9)$ \\
\hline & Rural & 2006-2015 & $-4.0^{\star}(-7.0,-0.9)$ & & & $-4.0^{\star}(-7.0,-0.9)$ \\
\hline \multirow[t]{12}{*}{ ICC } & Total & 2006-2015 & $3.1^{*}(0.2,6.1)$ & & & $3.1^{*}(0.2,6.1)$ \\
\hline & Age group & & & & & \\
\hline & $0-44$ & 2006-2015 & $2.3(-3.5,8.5)$ & & & $2.3(-3.5,8.5)$ \\
\hline & $45-54$ & 2006-2015 & $1.9(-2.9,6.9)$ & & & $1.9(-2.9,6.9)$ \\
\hline & $55-64$ & 2006-2015 & $3.4^{\star}(0.5,6.3)$ & & & $3.4^{*}(0.5,6.3)$ \\
\hline & $\geq 65$ & 2006-2015 & $3.8^{\star}(1.1,6.7)$ & & & $3.8^{\star}(1.1,6.7)$ \\
\hline & Sex & & & & & \\
\hline & Male & 2006-2015 & $3.9^{*}(0.6,7.2)$ & & & $3.9^{*}(0.6,7.2)$ \\
\hline & Female & 2006-2015 & $2.1(-0.5,4.7)$ & & & $2.1(-0.5,4.7)$ \\
\hline & Area & & & & & \\
\hline & Urban & 2006-2015 & $2.8(-0.4,6.0)$ & & & $2.8(-0.4,6.0)$ \\
\hline & Rural & 2006-2015 & $5.8(-1.8,13.9)$ & & & $5.8(-1.8,13.9)$ \\
\hline
\end{tabular}

*, The APC or AAPC is significantly different from zero $(\mathrm{P}<0.05)$. HCC, hepatocellular carcinoma; ICC, intrahepatic cholangiocarcinoma; APC, annual percentage change; AAPC, average annual percentage change. 